\title{
Clinical Characteristics and Patient-Reported Outcomes of Primary Care Physiotherapy in Patients with Whiplash-Associated Disorders: A Longitudinal Observational Study
}

This article was published in the following Dove Press journal:

Patient Preference and Adherence

Rob AB Oostendorp, (iD) ${ }^{1-4} \mathrm{JW}$ Hans Elvers, (iD) ${ }^{5,6}$ Emiel van Trijffel, ${ }^{7,8}$ Geert M Rutten, ${ }^{9,10}$ Gwendolyne GM Scholten-Peeters, (ID) " Marcel Heijmans, ${ }^{4}$ Erik Hendriks, ${ }^{12,13}$ Emilia

Mikolajewska, (ID) ${ }^{14,15}$ Margot De Kooning, (ID) ${ }^{3,16}$ Marjan Laekeman, iD ${ }^{17,18}$ Jo Nijs, iD ${ }^{3,16,19}$

Nathalie Roussel, (iD ${ }^{20}$ Han Samwel ${ }^{21}$

'Scientific Institute for Quality of Healthcare, Radboud University Nijmegen Medical Centre, Nijmegen, the Netherlands; ' Department of Manual Therapy, Faculty of Medicine and Pharmacy, Vrije Universiteit Brussel, Brussels, Belgium; ${ }^{3}$ Pain in Motion International Research Group, Department of Physiotherapy. Human Physiology and A Anatomy, Faculty of Physical Education and Physiotherapy Vrije Universiteit Brussel, Brussels, Belgium; ' ${ }^{4}$ Practice Physiotherapy and Manual Therapy, Heeswijk-Dinther, the Netherlands; ' ${ }^{5}$ epartment of Public Health and Research, Radboud University Nijmegen Medical Centre, Nijmegen, the Netherlands; 'Department of Allied Health Care, Methodological Health-Skilled Institute, Beuningen, the Netherlands: ${ }^{7}$ Department of Master Education SOMT University of Physiotherapy Amersfort, the Neth B D Department of Physiotherapy, Human Physiology and Anatomy, Faculty of Physical Education and Physiotherapy Vrije Universiteit Brussel, Brussels, Belgium; ' Institute of Health Studies, Faculty of Health and Social Studies, HAN University of Applied Science, Nijmegen, the Netherlands; ${ }^{10}$ Campus Venlo, Faculty of Science and Engineering Maastricht University, Maastricht, the Netherlands:

"Department of Human Movement Sciences, Faculty of Behavioral and Movement Sciences, Vrije Universiteit Amsterdam, Amsterdam Movement Sciences, Amsterdam, the Netherlands; '2 Department of Epidemiology, Center of Evidence Based Physiotherapy, Maastricht University, Maastricht, the Netherlands; ${ }^{3}$ Practice Physiotherapy 'Maasstaete, Druten, the Netherlands; ${ }^{14}$ Department of Physiotherapy, Ludwik Rydygier Collegium Medicum in Bydgoszcz, Nicolaus Copernicus University, Toruń, Poland; ${ }^{15}$ Neurocognitive Laboratory, Centre for Modern Neurocognitive Laboratory, Centre for Modern
Interdisciplinary Technologies, Nicolaus Copernicus Interdisciplinary Technologies, Nicolaus Copernicus
University, Toruń, Poland; ${ }^{6}$ Department of Physical Medicin University, Toruń, Poland; ${ }^{16}$ Department of Physical Medicine
and Physiotherapy, University Hospital Brussels, Brussels, Belgium; ${ }^{17}$ Department of Nursing Sciences, Ph.D.-Kolleg Faculty of Health, University Witten/Herdecke, Witten, Germany; ${ }^{18}$ Department of Physiological Psychology, University of Bamberg Bamberg Germany: ${ }^{19}$ Inttitute of Neuroscience and Physiology, University of Gothenburg, Gothenburg, Swedn, Department Rehabilitation Sciences (MOVANT), Faculty of Medicine and Health Sciences, University of Antwerp, Antwerp, Belgium; ${ }^{21}$ Revalis Pain Rehabilitation Centre, S Hertogenbosch, the Netherlands

Correspondence: Rob AB Oostendorp

Scientific Institute for Quality of Healthcare, Radboud University Nijmegen Medical Centre, p/a Oude Kleefsebaan 325, AT Berg En Dal 6572, Nijmegen, the Netherlands

$\mathrm{Tel}+3 \mid 246423419$

Email oostendorp.rob@gmail.com
Background: Whiplash-associated disorders (WADs) constitute a state of health characterized by a wide diversity of symptoms as a result of impairments of functions, activity limitations, and participation restrictions. Patient-reported outcome measurements (PROMs) and patient-reported outcomes (PROs) seem appropriate when describing and evaluating the health status of patients with WAD.

Aim: To measure the use of PROMs and PROs as quality indicators in clinical reasoning, and to analyze and evaluate pre- and post-treatment 'pain intensity' and 'functioning', and for 'perceived improvement' in patients with WAD in primary care physiotherapy practice by year of referral, with the phase after accident and prognostic health profile embedded in the clinical reasoning process. Materials and Methods: Data were collected over a period of 10 years. Pain intensity, functioning, and perceived improvement were measured using the Visual Analogue Scale for Pain (VAS-P), the Neck Disability Index (NDI) and the Global Perceived Effect scale (GPE). Pre- and post-treatment mean differences were tested for statistical significance and compared to minimal clinically important differences (MCID). Effect sizes were expressed as Cohen's d. Multivariable regression analysis was performed to explore independent associations of year of referral, phase after the accident, and the patient's prognostic health profile with post-treatment pain intensity and functioning.

Results: A consecutive sample of 523 patients was included. Pre- and post-treatment mean differences on VAS-P and NDI were statistically significant $(P<0.000)$ and clinically relevant, with 'large' effect sizes for pain intensity and functioning. MCIDs were achieved by $80 \%$ for VAS-P and for $60 \%$ for NDI. Year of referral and phase after the accident were independently associated with worse post-treatment functioning. About half of the patients $(\mathrm{n}=241[46.1 \%])$ perceived themselves as improved.

Conclusion: The PROMs and PROs pain intensity, functioning and perceived improvement were integrated as quality indicators in the physiotherapy clinical reasoning process for patients with WAD. Significant differences in pain intensity and functioning were found but were unrelated to year of referral, phase after whiplash-related injury or prognostic health profile. The MCID VAS-P scores did not differ depending on experienced pain.

Keywords: whiplash-Associated Disorders, neck pain, physiotherapy, patient-reported outcomes measures, routinely collected data

\section{Introduction}

Neck pain constitutes a major health problem in the general population, ${ }^{1-3}$ and may be associated with many different prognostic factors. One frequently reported cause 
of (persistent) neck pain is traumatic injury, usually as a result of a motor vehicle accident. Following injury, many patients report a complex of health-related symptoms such as neck pain, arm pain, headache, dizziness, and visual and auditory symptoms, hence the term Whiplash-Associated Disorder (WAD). ${ }^{4,5}$ This disorder is also characterized by poor coping strategies such as fear avoidance behavior, and by poor outcomes such as activity limitations and restricted participation. Treatment effectiveness and treatment outcomes after whiplash-related injury remain challenging issues, and both show room for improvement. ${ }^{6-8}$ Due to a range of issues including impairments of sensory functions, pain and neuromusculoskeletal functions, mental functions, activity limitations and participation restrictions, patient-reported outcome measurements (PROMs) are ideally suited to the evaluation of patient-reported outcomes (PROs) in patients with WAD, ${ }^{9,10}$

PROMs are defined as: ' $\ldots$ any measurement of the status of a patient's health condition that comes directly from the patient without interpretation of the patient's response by a clinician or anyone else, ${ }^{9}$ while PROs are defined as '.... health outcomes directly reported by the patient who experienced it'. ${ }^{11}$ PROMs and PROs are often used as quality indicators in physiotherapy clinical practice. $^{12,13}$ Quality indicators have been defined as 'measurable elements of practice performance for which there is evidence or consensus that they can be used to assess the quality of care provided'. ${ }^{14}$ In this study, PROMs are used as process indicators and PROs as outcome indicators.

A number of recovery patterns in relation to whiplashrelated injury have been reported but little is known concerning the variability of recovery over time. As most studies cease follow-up after one year, ${ }^{15-18}$ longitudinal studies evaluating the long-term variability of recovery are sparse, although a few studies have evaluated recovery patterns after periods of 5, 15, or 17 years. ${ }^{19-21}$ Around half of patients report persistent or residual symptoms (such as neck pain, headache, activity limitations and participation problems) a long time after an accident. ${ }^{19-22}$ High pain intensity and pain-related disability are the most consistent prognostic factors for prolonged activity limitations and participation problems. ${ }^{5,23,24}$ Prognostic health profiles were introduced in the first publication of Dutch guideline Whiplash and Physiotherapy. ${ }^{25,26}$ A prognostic health profile can be defined as a complex of positive and negative variables that can be used to estimate the clinical assessment including treatment plan and the chance of recovery, ${ }^{27}$ specifically the chance of functional recovery in patients with WAD.

Since 1993, the Royal Dutch Association for Physical Therapy has been continuously developing and implementing guidelines, including 'Physiotherapy Documentation', 28-31 'Physiotherapy and Whiplash',25,26 and 'Neck Pain', ${ }^{32,33}$ with the goal of optimizing registration of the clinical reasoning process in patients with WAD based on the phases after whiplash-related accident ${ }^{4}$ and on prognostic health profiles. ${ }^{34}$

Use of the PROMs 'pain intensity', 'functioning' and 'perceived recovery' is recommended by and integrated in the Dutch guideline 'Physiotherapy and Whiplash'. ${ }^{25,26}$ Recommendations concerning the use of these PROMs as process indicators and PROs as outcome indicators when embedded in the clinical reasoning process have been implemented in Dutch primary care physiotherapy practices. $^{26,34}$

The primary aim of the present study was to measure the use, in clinical reasoning, of PROMs as process indicators and PROs as outcome indicators. A secondary aim was to analyze and evaluate the routinely collected preand post-treatment PROs 'pain intensity', 'functioning', and 'perceived recovery' in WAD patients in primary care physiotherapy practices in relation to the year of referral, phase after whiplash-related injury and prognostic health profile.

\section{Materials and Methods \\ Design}

In 2016, a quality improvement study was launched that focused on the quality of primary care physiotherapy management in patients with WAD. The study was based on an existing dataset (routinely collected dataset whiplash-associated disorders [RCD-WAD]), and details of the design and execution of this retrospective cohort study have been published elsewhere. ${ }^{35,36}$

The Medical Ethics Committee of Radboud University Medical Centre Nijmegen, The Netherlands waived the requirement for ethical approval. Retrospective research based on anonymized patient files does not fall within the scope of the Medical Research Involving Human Subjects Act because the subject is not physically involved in the research. The data are already available and not collected specifically for this project, and subjects do not have to change their behavior for this project. 


\section{Practice Population}

Patients were recruited using a consecutive sampling strategy. ${ }^{37}$ Patients with whiplash-related symptoms were referred by general physicians or medical specialists to two primary care physiotherapy practices in the South of the Netherlands. All patients who met the Quebec Task Force Classification of WAD-1, WAD-2 or WAD-3 were assessed. Following initial screening related to the 5D's +1 (dizziness, diplopia, drop attacks, dysarthria, dysphagia + nausea), patients with $\geq 2$ Ds were referred back to their general physician. In total, 523 patients were included.

\section{Data Collection}

The registration of outcome-related data in the form of PROMs began in 2002. Data on PROMs were collected over a period of 10 years (2002-2011). The current analysis concerns outcome evaluations over this period.

\section{Assessments}

Patient assessment was based on a clinical reasoning process consisting of nine steps, including administration, history taking, objectives of examination, clinical examination, conclusion, treatment plan and goals, treatment modalities, evaluation and discharge. Details of the complete clinical reasoning process can be found elsewhere. ${ }^{35}$ All variables of the clinical reasoning process were operationalized at several different levels of measurement (nominal, ordinal, interval and ratio). See Supplementary file 1.

History taking was used to assess baseline characteristics, including: sociodemographic characteristics (age, gender, educational level and employment status), accident-related characteristics (direction of impact, anticipation of collision, type of trauma, classification WAD, period since accident, and onset of symptoms), pre-existing health status (functioning problems, relevant medication use, previous neck injury, previous neck pain and stiffness, and pain elsewhere), previous diagnostics and treatment (medical imaging diagnostics, use of cervical soft collar, pain medication, [manual] physiotherapy, recovery after treatment), current health status and recovery rate (recovery since accident, functioning problems, pain medication, type and number of symptoms), actual pain behavior and fear avoidance (by means of observation of pain behavior, modified Waddell's signs, Pain Coping Inventory [PCI], Fear Avoidance Beliefs Questionnaire [FABQ], and prognostic health profile).
The PCI is a 33-item questionnaire measuring active coping (PCI-A: 12 items; total score range 12-48) and passive coping (PCI-P: 21 items; total score range 21-84). Items are scored on a 4-point Likert scale ranging from 1 (hardly ever) to 4 (very often). PCI cutoff scores are $\geq 24$ for active coping, and $\geq 42$ for passive coping. ${ }^{38}$ The clinimetric properties of the PCI range from acceptable to good. ${ }^{39}$

The FABQ-Dutch Version (DV) is a 16-item (5 items were not scored) questionnaire measuring fear avoidance beliefs regarding physical activities (FABQ-DV-A: 4 items; total score range: $0-24$ ) and work-related activities (FABQ-DV-W: 7 items; total score range: 0-42). Items are scored on a 7-point Likert scale ranging from 0 (completely disagree) to 6 (completely agree). FABQ-DV cutoff scores are $>15$ at risk for pain avoiding behavior, and $>34$ at risk for not returning to work. ${ }^{40}$ The clinimetric properties of the FABQ-DV range from acceptable to good. ${ }^{41}$

Prognostic health profiles were first introduced with the publication of the Dutch guideline 'Whiplash and Physiotherapy' ${ }^{25,26}$ Based on pre-existing symptoms and previous prognostic factors for recovery, patients were classified as Profile A (normal recovery, pain low intensity, decreasing pain, increasing activities, active coping and no fear avoidance), as Profile B (uncertain recovery, medium pain intensity, persistent pain, persistent activity limitations, inconclusive coping and fear avoidance) or as Profile C (delayed recovery, high pain intensity, increasing pain, decreasing activities, passive coping and fear avoidance).

\section{Intervention}

Clinical data related to the six phases of the Quebec Task Force $\mathrm{WAD}^{4}$ guided treatment goals and treatment options, combined with the prognostic health profiles (Phase 1: $<7$ days; acute; normal recovery; Phase 2: 1-3 weeks; acute; normal recovery; phase 3a: 4-6 weeks; subacute; uncertain recovery; phase 3b: 4-6 weeks; subchronic; delayed recovery; Phase 4a: 7-12 weeks; subacute; uncertain recovery; phase 4b: 7-12 weeks; subchronic; delayed recovery; Phase 5: 3-6 months; chronic; no recovery; Phase 6: $>6$ months; chronic; no recovery). A complete flowchart illustrating the clinical reasoning process of physiotherapy management in patients with WAD has been presented elsewhere. ${ }^{35}$ A summary of treatment goals and physiotherapy modalities per phase 1-6, together with outcomes, is presented in Table 1 . 
Table I Phase- and Profile-Based Treatment Goals and Physiotherapy Treatment Modalities, Together with Outcomes for Management in Patients with Whiplash-Associated Disorders (WAD)

\begin{tabular}{|c|c|c|c|}
\hline $\begin{array}{l}\text { Phase After Whiplash- } \\
\text { Related Injurya, Combined } \\
\text { with Prognostic Health } \\
\text { Profile }\end{array}$ & Treatment Goals & Interventions $^{c}$ & Outcomes \\
\hline $\begin{array}{l}\text { Phase I (<7 days) } \\
\text { Profile A }\end{array}$ & $\begin{array}{l}\text { Reducing pain } \\
\text { Providing information } \\
\text { Explaining consequences for } \\
\text { functioning and } \\
\text { underlying pain mechanisms }\end{array}$ & $\begin{array}{l}\text { Education } \\
\text { Coaching } \\
\text { Active exercise therapy } \\
\text { If indicated: cervical soft } \\
\text { collar (<I week) }\end{array}$ & \multirow[t]{8}{*}{$\begin{array}{l}\text { Patient-reported outcomes. Pain intensity. } \\
\text { Functioning/Activity limitations. Perceived } \\
\text { recovery. Return to work participation } \\
\text { Care-related outcomes. Subjective evaluation. } \\
\text { Reason for discharge. Duration of treatment } \\
\text { period. Number of treatment sessions }\end{array}$} \\
\hline $\begin{array}{l}\text { Phase } 2 \text { (I-3 weeks) } \\
\text { Profile A }\end{array}$ & $\begin{array}{l}\text { See Phase I + improving } \\
\text { musculoskeletal function }\end{array}$ & $\begin{array}{l}\text { See Phase I } \\
\text { If indicated: massage } \\
\text { therapy ( }<2 \text { weeks) and } \\
\text { manual therapy } \\
\text { (mobilization) }\end{array}$ & \\
\hline $\begin{array}{l}\text { Phase } 3 \text { ( } 4-6 \text { weeks) } \\
\text { Profile A }\end{array}$ & $\begin{array}{l}\text { See Phase } 2+\text { increasing } \\
\text { activities and participation }\end{array}$ & $\begin{array}{l}\text { See Phase I } \\
\text { Physical loading exercise } \\
\text { therapy }\end{array}$ & \\
\hline $\begin{array}{l}\text { Phase } 3 \text { ( } 4-6 \text { weeks) } \\
\text { Profile B }\end{array}$ & $\begin{array}{l}\text { Explaining underlying pain } \\
\text { mechanisms } \\
\text { Improving active coping } \\
\text { Decreasing fear avoidance } \\
\text { Increasing physical capacity } \\
\text { Increasing activities and } \\
\text { participation }\end{array}$ & $\begin{array}{l}\text { Pain education } \\
\text { Exercise therapy based on } \\
\text { cognitive and } \\
\text { physical principles }\end{array}$ & \\
\hline $\begin{array}{l}\text { Phase } 4 \text { (7-12 weeks) } \\
\text { Profile A }\end{array}$ & $\begin{array}{l}\text { See Phase } 3 a+\text { minimizing } \\
\text { delay in work participation }\end{array}$ & $\begin{array}{l}\text { See Phase 3a } \\
\text { Exercise therapy (graded } \\
\text { activity) }\end{array}$ & \\
\hline $\begin{array}{l}\text { Phase } 4 \text { ( } 7-12 \text { weeks) } \\
\text { Profile B }\end{array}$ & See Phase $3 b$ & $\begin{array}{l}\text { See Phase } 3 b \\
\text { Exercise therapy (graded } \\
\text { exposure) }\end{array}$ & \\
\hline $\begin{array}{l}\text { Phase } 5 \text { ( } 3-6 \text { months) } \\
\text { Profile C }\end{array}$ & See Phase 3b & See Phase 4 & \\
\hline $\begin{array}{l}\text { Phase } 6 \text { (>6 months) } \\
\text { Profile C }\end{array}$ & See Phase $3 b$ & See Phase 5 & \\
\hline
\end{tabular}

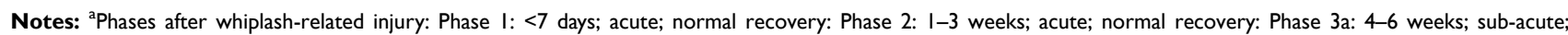
inconclusive recovery: Phase 3b: 4-6 weeks; sub-chronic; delayed recovery: Phase 4a: 7-12 weeks; sub-acute; inconclusive recovery: Phase 4b: 7-12 weeks; sub-chronic;

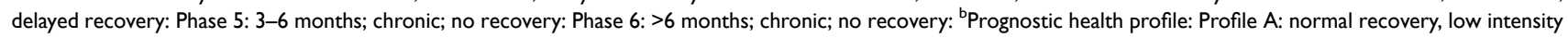
of pain, decreasing pain, increasing activities, active coping, no fear avoidance: Profile B: inconclusive recovery, middle intensity of pain, persistent pain, persistent activity limitations, inconclusive coping, inconclusive fear avoidance: Profile C: delayed recovery, high intensity of pain, increasing pain, decreasing activities, passive coping, fear avoidance: ' Classification Allied Health Care, version Physiotherapy: I. History Taking; 2. Inspection and observation; 3. Palpation; 4. Active exercise therapy; 5. Passive exercise therapy (manual therapy); 6. Massage therapy; 7. Modalities of physical therapy (ie, low- and high-frequency electrotherapy); 8. Coaching; 9 . Education.

Participating physiotherapists managed patients according to a dynamic protocol consisting of three recovery rate-dependent prognostic health profiles, embedded in the six phases after whiplash-related accident. ${ }^{34}$ The combined content of treatment modalities was based on the treatment goals per time phase, the prognostic health profiles, and the best available evidence. $^{42-47}$

\section{Evaluation}

In addition to the traditional approach of directly asking a patient about the perceived result of treatment, one of the 
most rapidly evolving recommendations of the Dutch guideline 'Physiotherapy and Whiplash' in $2002^{25,26}$ involved the introduction of pre- and post-treatment PROMs in clinical practice.

\section{Patient-Reported Outcomes and Patient-Reported Outcome Measurements}

The PROs were based on guideline-recommended outcomes and expressed as PROM scores, which included measures of neck pain intensity, functioning, and perceived recovery. ${ }^{48}$ These recommendations were transformed into quality indicators by phrasing them as the average degree (in \%) to which patients were subjected to a methodically performed clinical reasoning process (ie, the average degree [in \%] to which pre- and post-treatment pain intensity and functioning were measured and noted). Three newly formulated quality indicators were added to the earlier developed and tested set of quality indicators that were already embedded in the clinical reasoning process for physiotherapy in patients with WAD..$^{35,36}$

Pain intensity was measured using the Visual Analogue Scale for Pain (VAS-P), which consists of a horizontal $100 \mathrm{~mm}$ line scored from 0 (no pain) to 100 (worst imaginable pain). ${ }^{49,50}$ The minimal clinically important difference (MCID) on VAS-P is $20 \mathrm{~mm}(\geq 30 \%$ of the initial score). ${ }^{51,52}$ The VAS-P has proved to be reliable, valid and sensitive to change. ${ }^{53,54}$ Initial score of $\geq 55 \mathrm{~mm}$ on VAS-P is useful cut-off score to predict poor functional recovery. ${ }^{23}$

Functioning or activity limitation was measured using the Neck Disability Index (NDI). ${ }^{55,56}$ The NDI is a selfreport questionnaire that measures activity limitations due to neck pain resulting from whiplash-related injuries. The NDI consists of 10 items that address pain intensity, personal care, lifting, reading, headache, concentration, work, driving, sleeping, and recreation. Each item is scored from 0 (no activity limitation) to 5 (major activity limitation). Functioning-related outcome measures (ie, mobility, selfcare, domestic life, work and employment) included the Neck Disability Index (NDI). The total score range is 0-50 points, with increasing scores representing increasing impairments and disabilities due to neck pain. The MCID on the NDI is $\geq 11$ points lower than the initial score. ${ }^{52,57-59}$ The NDI has been translated into Dutch (Dutch version; DV). ${ }^{60}$ The NDI-DV has proved to be reliable, valid and sensitive to change, and has high internal consistency. ${ }^{61,62}$ Initial score of $>29 \%$ from $0-50$ points NDI is useful cutoff score to predict poor functional recovery. ${ }^{23}$
Patients were asked to complete the outcome 'perceived improvement', rating the pre- to post-intervention perceived change in improvement from 1 (completely improved) to 6 (much worse) ${ }^{51,63}$ The Global Perceived Effect (GPE) is a reliable, valid and responsive measure of health status in patients with musculoskeletal pain. ${ }^{63}$

Participation or participation restrictions in relation to return to work were queried and rated as 1 (no return), 2 (return with adjustments) or 3 (return without adjustments) of patients who were employed before the whiplashrelated accident.

\section{Statistical Analysis}

Analyses were performed with Statistics 9.0. Descriptive statistics (frequency, means and SDs) were used to characterize the study population's demographics, accidentand previous and current health-related characteristics, previous diagnostics and treatment, and current functional characteristics. The dataset was checked for missing values. The normality of continuous variables was tested using the Kolmogorov-Smirnov test.

For PROM scores, means and standard deviations (SD) were calculated for pre- and post-treatment scores on pain intensity (VAS-P) and functioning (NDI). The pre- and post-treatment differences in these average scores (including confidence intervals [CI] of $95 \%$ [0.05]) were recorded for the total study population $(\mathrm{n}=523)$, per year of referral (10-year period [1-10]), per phase (phases 1-6) after whiplash-related injury, and per prognostic health profile (profile A, B and C).

Pre- and post-treatment mean differences were tested for statistical significance with the paired sample $t$-test ( $\alpha$ value set at 0.05 ), and for clinical relevance by comparison to established data for the minimal clinically important difference (MCID). Differences $\geq 30 \%$ on the initial score of VAS-P and $\geq 11$ points on $\mathrm{NDI}^{51}$ were considered clinically relevant. Numbers of patients who reached the MCIDs on VAS-P and NDI were calculated and expressed as percentages. Effect size (ES) as magnitude of the difference between the means of pre- and post-treatment scores was expressed in Cohen's $d$ with $0.21-0.50,0.51-$ 0.80 and $>0.81$ considered as small, medium and large effects, respectively. ${ }^{64}$ Percentage scores were calculated for the three classes of return to work participation.

Percentages scores were also calculated for the perceived improvement. The scores were categorized as 'improved' (very good, good, and fairly improved), 'no change' ('same as before') and 'worse (worse and much 
worse) ${ }^{51} \mathrm{~A}$ Chi-square test of independence was used to analyze a GPE frequency table constituted of those who did or did not improve $(\alpha=0.05)$.

Finally, multivariable regression analysis was performed to explore independent associations of year of referral, phase after accident, and patients' prognostic health profile with post-treatment pain intensity and functioning. Beta regression coefficients were estimated with $P=0.05$, corrected for pre-treatment scores on VAS and NDI, respectively.

\section{Results}

\section{The Practice Population}

A consecutive sample of 529 patients was originally included, of whom 523 were referred by a GP $(n=342$; $65.4 \%)$ or medical specialist $(n=84 ; 16.1 \%)$, and 97 patients visited the practice via self-referral $(n=97$; $18.5 \%$ ). Six patients were subsequently referred back to their general physician due to suspicion of serious pathology.

All patients were assessed by one of eight physiotherapists working in two primary care physiotherapy practices. The mean age of the physiotherapists $(n=8)$ at the beginning of the study was 46.2 years (SD 5.6), six were male, and six were manual physiotherapists. The range of experience regarding treatment of patients with whiplashrelated injuries varied between 6 and 28 years.

Baseline characteristics of the patients, with no missing values $(\mathrm{n}=523)$, are presented in Table 2. Seventy-six percent of patients were female, with a mean age of 43.4 years (SD 13.1). Most patients ( $\mathrm{n}=406 ; 77.6 \%$ ) were classified as WAD-2, with a delayed recovery, and were referred 7 weeks to $>6$ months after an accident $(n=293$; $56.0 \%)$. Fifty-five patients (10.5\%) reported a previous whiplash injury and 96 patients (18.4\%) previous neck pain and stiffness. Half of the patients had been previously treated with several interventions such as pain medication $(\mathrm{n}=221 ; 42.3 \%)$, cervical soft collar $(\mathrm{n}=295 ; 56.4 \%)$, and (manual) physiotherapy ( $\mathrm{n}=234 ; 44.7 \%)$. In 180 patients (34.4\%) the results of the earlier treatment were inconclusive, in 104 patients $(19.9 \%)$ functioning was estimated to have stabilized, and 212 patients (40.5\%) showed a deterioration in functioning.

A number of potentially negative prognostic factors for recovery were reported, including pain intensity, level of functioning, recovery rate since accident (uncertain
Table 2 Baseline Characteristics in Physiotherapy Management in Patients with Whiplash-Associated Disorders

\begin{tabular}{|c|c|}
\hline Total $n=523: n(\%)$ Unless Othe & \\
\hline Sociodemographic characteristics & \\
\hline Age (year) (mean; SD) & \\
\hline - Female & $43.4(13.1)$ \\
\hline - Male & $39.8(13.4)$ \\
\hline Gender (female) & $396(75.7)$ \\
\hline Educational level & \\
\hline - Lower (primary school) & $283(54.1)$ \\
\hline - Intermediate (secondary school) & $147(28.1)$ \\
\hline - Higher (post-secondary school) & $93(17.8)$ \\
\hline Employment status & \\
\hline - Unemployed/job seeking & $180(34.4)$ \\
\hline - In work & $277(53.0)$ \\
\hline - Retired & $66(12.6)$ \\
\hline Accident-related characteristics & \\
\hline Direction of impact (back) & $356(68.2)$ \\
\hline Anticipated collision (no) & $4 \mid 4(79.2)$ \\
\hline Type of trauma & \\
\hline - Neck & $349(66.7)$ \\
\hline - Neck and head & $138(26.4)$ \\
\hline - Other type & $36(6.9)$ \\
\hline Classification WAD ${ }^{a}$ & \\
\hline - WAD-I & $38(7.3)$ \\
\hline - WAD-2 & $406(77.6)$ \\
\hline - WAD-3 & $79(15.1)$ \\
\hline - WAD-4 & - \\
\hline Period since accident & \\
\hline - $<7$ days & $14(2.7)$ \\
\hline - I-3 weeks & $98(18.7)$ \\
\hline - 4-6 weeks & $118(22.6)$ \\
\hline - 7-12 weeks & $114(21.8)$ \\
\hline - 3-6 months & $123(23.5)$ \\
\hline - >6 months & $56(10.7)$ \\
\hline Onset of symptoms & \\
\hline - Immediately & $109(20.8)$ \\
\hline - $\leq 2$ days & $336(64.2)$ \\
\hline - 3-7 days & 78 (14.9) \\
\hline - >I week & - \\
\hline Pre-existing health status & \\
\hline Functioning problems & \\
\hline - Activity limitation (yes) & $91(17.4)$ \\
\hline - Participation problems (yes) & $74(14.1)$ \\
\hline - Job-related problems (yes) & $60(11.5)$ \\
\hline
\end{tabular}

(Continued) 
Table 2 (Continued).

\section{Total n=523: $n$ (\%) Unless Otherwise Stated}

\begin{tabular}{|c|c|}
\hline Relevant medication use (yes) & $74(14.1)$ \\
\hline Previous whiplash injury (yes) & $55(10.5)$ \\
\hline Previous neck pain and stiffness (yes) & $96(18.4)$ \\
\hline Pain elsewhere (yes) & $115(22.0)$ \\
\hline \multicolumn{2}{|l|}{ Previous diagnostics and treatment } \\
\hline Medical imaging diagnostics (yes) & $90(17.2)$ \\
\hline $\begin{array}{l}\text { Cervical soft collar (yes) } \\
\text { - Weeks (mean; SD) }\end{array}$ & $\begin{array}{l}295(56.4) \\
3.5(1.6)\end{array}$ \\
\hline Pain medication (yes) & $221(42.3)$ \\
\hline $\begin{array}{l}\text { (Manual) physiotherapy (yes; } \mathrm{n}=234 \text { ) } \\
\text { - Active exercise therapy } \\
\text { - Manual therapy } \\
\text { - Active exercise therapy + manual therapy } \\
\text { - Massage therapy } \\
\text { - Combined therapy }\end{array}$ & $\begin{array}{l}76(32.5) \\
36(15.4) \\
25(10.7) \\
20(8.5) \\
77(32.9)\end{array}$ \\
\hline $\begin{array}{l}\text { Recovery after treatment } \\
\text { - Fully } \\
\text { - Partially } \\
\text { - Stabilization } \\
\text { - Deterioration } \\
\text { - Inconclusive }\end{array}$ & $\begin{array}{l}- \\
27(5.2) \\
104(19.9) \\
212(40.5) \\
180(34.4)\end{array}$ \\
\hline
\end{tabular}

Current health status and recovery rate

Recovery since accident

- Normal

- Inconclusive

- Deterioration

Functioning problems

- Impairments in musculoskeletal neck functions (yes)

- Activity limitation (yes)

- Participation problems (yes)

- Job-related problems (yes)

\begin{tabular}{|c|c|}
\hline Pain medication (yes) & $|3|(25.0)$ \\
\hline $\begin{array}{l}\text { Type and number of symptoms } \\
\text { - } \leq 3 \text { : neck pain, stiffness, decreased ROM } \\
\text { - } 4-6: \text { + dizziness, headache and tinnitus } \\
\text { - 7-9: + cognitive impairments } \\
\text { - }>9 \text { : + rest }\end{array}$ & $\begin{array}{l}10(1.9) \\
165(31.5) \\
344(65.8) \\
4(0.8)\end{array}$ \\
\hline Pain intensity (VAS-P $\geq 55 \mathrm{~mm} ; 0-100 \mathrm{~mm})^{c}$ & $330(63.1)$ \\
\hline Functioning (NDI >29\%; 0-50 points) ${ }^{d}$ & $514(98.3)$ \\
\hline
\end{tabular}

Current pain behavior and fear avoidance

\begin{tabular}{|l|l|}
\hline Observation pain behavior (yes) & $510(97.5)$ \\
\hline
\end{tabular}

(Continued)
Table 2 (Continued).

\begin{tabular}{|l|l|}
\hline \multicolumn{2}{|l|}{ Total n=523: n (\%) Unless Otherwise Stated } \\
\hline $\begin{array}{l}\text { Modified Waddell's non-organic physical signs } \\
\text { - } \leq 3\end{array}$ & $9(\mathrm{I} .7)$ \\
- $>3$ & $514(97.5)$ \\
\hline Pain Coping Inventory & \\
- PCl-Active (score: $12-48)$ (mean; SD) & $27.1(6.1)$ \\
- Active coping (score $\geq 24)$ & $396(75.7)$ \\
- PCI-Passive (score 2I-84) (mean; SD) & $54.2(13.3)$ \\
- Passive coping (score $\geq 42)$ & $416(79.5)$ \\
\hline Fear Avoidance Beliefs Questionnaire & \\
- FABQ-Activities (score: 0-24) (mean; SD) & $16.0(3.4)$ \\
- Risk for pain avoiding behavior (score >I5) & $346(66.2)$ \\
- FABQ-Work (score: 0-42) (n=354) (mean; SD) & $29.3(7.7)$ \\
- Risk for no return to work (score $>34)$ & $137(38.7)$ \\
\hline
\end{tabular}

Notes: ${ }^{a}$ Classification WAD: Whiplash-Associated Disorders: WAD 0: no neck symptoms, no physical sign(s); WAD I: neck pain, stiffness or tenderness only, no physical sign(s); WAD 2: neck symptoms and musculoskeletal sign(s); WAD 3: neck symptoms and neurological sign(s); WAD 4: neck symptoms and fracture or dislocation ${ }^{b}$ ROM: Range of Motion. 'VAS-P: Visual Analogue Scale for Pain: horizontal line of $100 \mathrm{~mm}$ scored from 0 (no pain) to 100 (worst imaginable pain). ${ }^{d} \mathrm{NDI}$ : Neck Disability Index: 10 items scored from 0 (no activity limitation) to 5 (major activity limitation); total score $0-50$. 'Modified Waddell's non-organic physical signs: superficial tenderness, non-anatomical tenderness, pain simulation test, cervical ROM, regional disturbance, overreaction ${ }^{e}$ Pain Coping Inventory $(\mathrm{PCl})$ : 33-item questionnaire measuring active coping (PCl-Active: 12 items [1248]; $\geq 24$ active coping) and passive coping ( $\mathrm{PCl}-\mathrm{P}: 2 \mathrm{I}$ items [2I-84]; $\geq 42$ passive coping). Items are scored on a 4-point Likert scale ranging from I (hardly ever) to 4 (very often). 'Fear Avoidance Beliefs Questionnaire (FABQ): 16-item questionnaire measuring fear avoidance beliefs related to physical activities (FABQActivities: 4 items [0-24]; $>15$ at risk for pain avoiding behavior), and workrelated activities (FABQ-Work: 7 items [0-42]; $>34$ at risk for no return to work). Items are scored on a 7-point Likert scale ranging from 0 (completely disagree) to 6 (completely agree)

$[\mathrm{n}=339 ; 64.8 \%]$ and deterioration $[\mathrm{n}=144 ; 27.5 \%])$, modified Waddell's non-organic physical signs (>3: 514 [97.5\%]), risk for poor functional recovery (VAS-P $\geq 55 \mathrm{~mm}: \mathrm{n}=330$ [63.1\%]; NDI >29\%: $\mathrm{n}=514$ [98.3\%]), risk for passive coping (PCI-P $\geq 42: \mathrm{n}=416$ [79.5\%]), risk for pain avoiding behavior (FABQ-A $>15: \quad n=346$ [66.2\%]), and risk for no return to work (FABQ-W $>34$ : $\mathrm{n}=137[38.7 \%])$.

\section{Quality Indicators}

Pre-treatment scores for pain intensity (VAS-P) and functioning (NDI) were implemented as process indicators in clinical reasoning (during the treatment plan phase), while post-treatment scores and perceived improvement were implemented as outcome indicators (during the evaluation phase). The new quality indicators met the performance target $(\geq 70 \%){ }^{35}$ 


\section{Patient-Reported Outcomes}

Outcomes including mean differences between pre- and post-treatment scores on VAS-P and NDI, effect sizes (Cohen's d), percentage of patients that reached MCIDs, changes in perceived improvement (percentage of "improved", "no change" or "worse") in the total group $(n=523)$ and per year of referral are presented in Table 3, per phase 1-6 after whiplash-related injury in Table 4 , and per prognostic health profile (profile A $(\mathrm{n}=40[7.6 \%])$, profile $B(n=339[64.8 \%])$ or profile $C(n=144[27.5 \%]))$ in Table 5.

\section{Year of Referral}

Pre- and post-treatment mean differences on VAS-P and NDI were statistically significant $(P<0.000)$ and clinically relevant for the total group and for the groups per year of referral (except for the NDI-MCID at years 5 and 6). The percentage of patients who reached MCIDs was noted for MCID VAS-P ( $\geq 30 \%$, ranging from 72.9 to $94.0 \%$ ) and for MCID NDI ( $\geq 11$ points, ranging from 48.8 to $80.8 \%$ ). The MCID for the total group was reached by $83.7 \%(n=443)$ for VAS-P and $59.7 \%(n=312)$ for NDI. A "large" effect size (Cohen's $d>0.81$ ) was noted for pain intensity, ranging from 1.61 (year 1) to 2.38 (year 4), and for functioning, ranging from 1.21 (year 7) to 2.01 (year 3). The effect size for the total group was also "large".

About half of the patients were "improved" according to the global perceived improvement scale $(\mathrm{n}=241$; $46.1 \%$ ), about two fifth "no change" ( $\mathrm{n}=199 ; 38.0 \%)$, and about one fifth "worse" $(\mathrm{n}=83 ; 15.9 \%)$ for the total group; about the same percentages per year of referral.

Multivariable regression analysis revealed that year of referral was independently associated with post-treatment worse functioning $(\beta 0.27, P<0.00$ ), but not with posttreatment pain intensity $(\beta 0.01, P 0.97)$.

\section{Phases After Whiplash-Related Injury}

Pre- and post-treatment mean differences on VAS-P and NDI were statistically significant $(P<0.000)$ and clinically relevant for the total group $(\mathrm{n}=523)$, and for the phases 1-6 after whiplash-related injury separately. The percentage of patients who reached MCIDs was noted for MCID VAS-P ( $\geq 30 \%$, ranging from 79.6 to $86.4 \%$ ) and for MCID NDI ( $\geq 11$ points, ranging from 53.6 to $68.4 \%$ ). Effect sizes for pain intensity were "large" (Cohen's d >0.81), ranging from 1.54 (phase 1) to 2.41 (phase 6), and were also "large" for functioning, ranging from 1.28 (phase 1) to 1.75 (phase 2). The effect size for the total group was "large". About half of the patients were "improved" according to the global perceived improvement scale $(\mathrm{n}=241 ; 46.1 \%)$.

Phase after the accident was independently associated with post-treatment worse functioning ( $\beta 0.45, P 0.03)$, but not with post-treatment pain intensity $(\beta 0.20, P 0.57)$.

\section{Prognostic Health Profiles}

Pre- and post-treatment mean differences on VAS-P and NDI were statistically significant $(\mathrm{p}<0.00)$ and clinically relevant for the total group $(\mathrm{n}=523)$ and for prognostic health profile A, profile $\mathrm{B}$ and profile $\mathrm{C}$ separately. The percentage of patients who reached MCIDs was noted for MCID VAS-P ( $\geq 30 \%$, ranging from 81.3 to $95.0 \%$ ) and for MCID NDI ( $\geq 11$ points, ranging from 57.2 to $67.5 \%$ ). Effect sizes for pain intensity and functioning across the prognostic health profiles were large (pain intensity ranging from 1.89 [profile $\mathrm{A}$ ] to 2.40 [profile $\mathrm{C}$ ]; functioning from 1.60 [profile A] to 1.66 [profile B]).

About half of the patients were "improved" according to the GPE $(n=241 ; 46.1 \%)$. The difference between "improved" and "worse" on the GPE was statistically significant for all profiles $(P<0.00)$.

Patient prognostic health profiles were not independently associated with post-treatment pain intensity $(\beta$ $0.80, P 0.40)$, nor with post-treatment functioning $(\beta$ $0.82, P 0.15)$.

\section{Employment}

Of the 523 patients, 423 patients $(80.9 \%)$ were employed at the moment of referral. At the end of their treatment period, 168 patients $(39.7 \%)$ did not return to work and remained on sick-leave, 123 patients $(29.1 \%)$ returned with adjustments, and $132(31.2 \%)$ returned without adjustments.

\section{Discussion}

In the description of clinical reasoning in patients with WAD, process and outcome indicators for physiotherapy represent an important step forwards in understanding the relationship between process and outcome. Having defined the benefits of using PROMs and PROs as the degree to which VAS-P, NDI and perceived improvement were used and noted in the clinical reasoning process, our analysis suggests that the use of these PROMs and PROs improved the quality of care.

In this study, we found statistically and clinically significant differences in pain intensity and functioning that 
\begin{tabular}{ll} 
Dovepress & Oostendorp et al \\
\hline
\end{tabular}

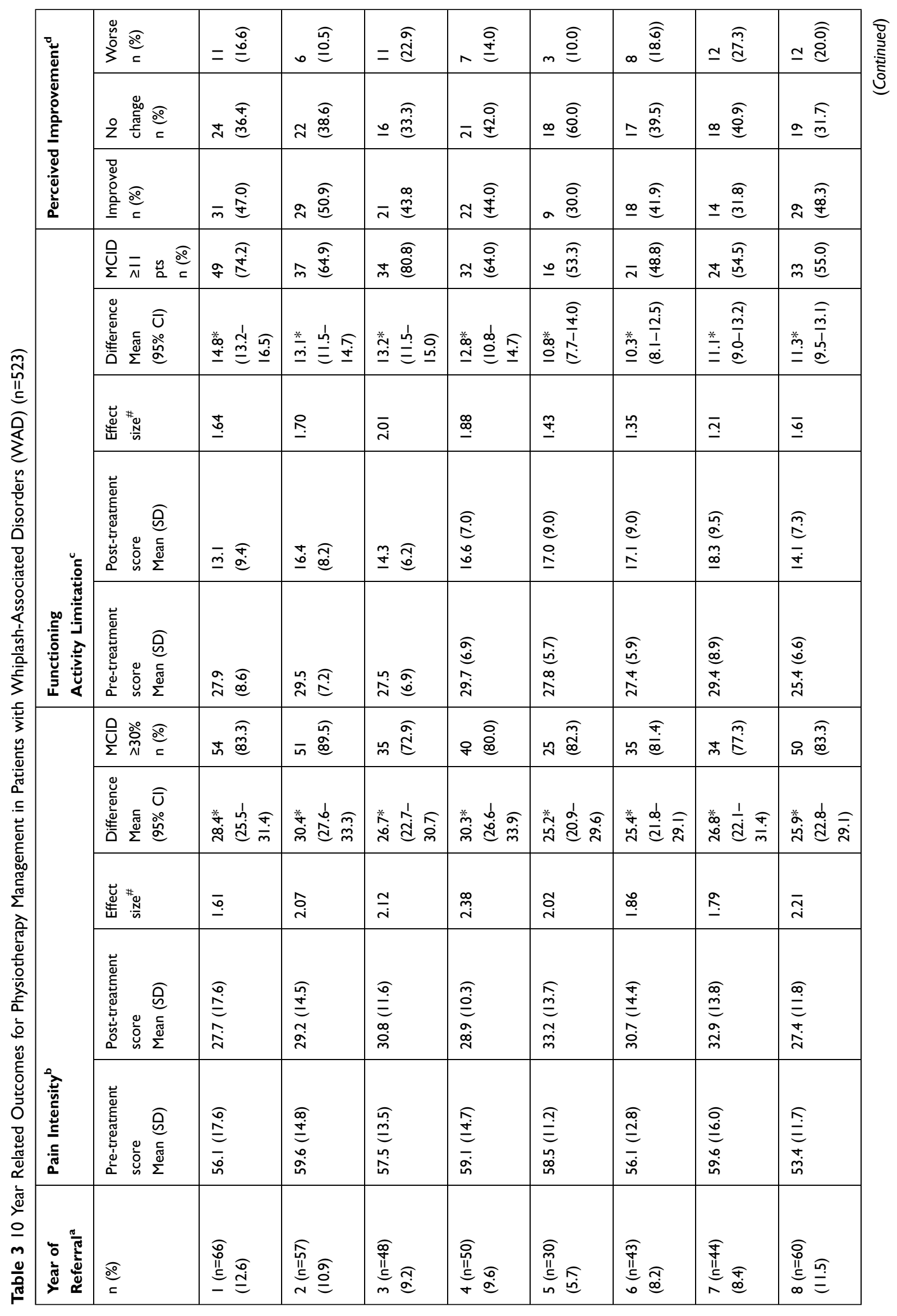

Patient Preference and Adherence 2020:14

submit your manuscript $\mid$ www.dovepress.com $\quad \mathbf{I 7 4 ~}$ 


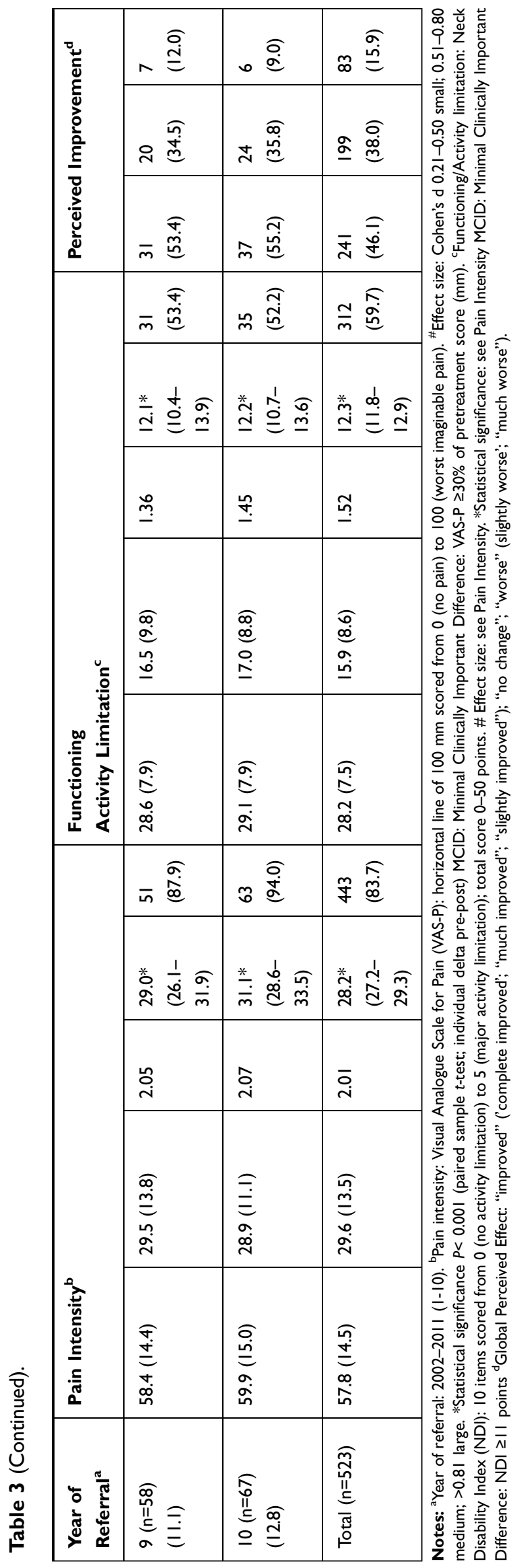

were unrelated to year of referral, phase after whiplashrelated injury or prognostic health profile. MCID values were approximately $80 \%$ for VAS-P and $60 \%$ for functioning (NDI). Perceived improvement was more likely with a positive (profile A) than with a negative prognostic health profile (profile C).

\section{Patient Population and Specialist Primary Care Physiotherapy Practice}

All patients were referred to two primary care physiotherapy practices, both of which were specialized in the assessment and management of patients with neck pain. With the exception of a few patients with red flags, complete data on all included patients were assessed in this retrospective cohort study. The characteristics of our patient sample were comparable to participants in other Dutch studies ${ }^{6-68}$ and to patients in international studies., ${ }^{69,70}$ and the characteristics of the participating physiotherapists were comparable to the national average. $^{71}$

\section{Patient-Reported Outcomes}

As mentioned in the introduction, longitudinal studies were identified that described patient follow-up at 1 year $^{15,18}$ or at 5,15 or 17 years ${ }^{19,21}$ following a motor vehicle accident. Although there are a great number of studies investigating prognostic factors in relation to the course of recovery in patients with WAD, to the best of the authors' knowledge, no previous study of equivalent duration has described the quality of the clinical reasoning process, including the integration of the PROMs and PROs "pain intensity", "functioning" and "perceived improvement" as indicators, in patients after WADrelated accident referred to specialist primary care physiotherapy practices.

\section{Year of Referral}

The period of time before referral after whiplash-related accident has shifted over the years, becoming longer. Unsurprisingly, referrals in the final years of the study included a higher proportion of chronic cases relative to the early years. This factor presumably explains the outcome of worse functioning as time progressed.

It is clear that over the years of referral most patients reached the MCID value of $\geq 30 \%$ for initial pain intensity score. Although a percentage and not a fixed number of $\mathrm{mm}$ was chosen as initial pain intensity threshold, an unanswered question is whether the MCID VAS-P score 


\begin{tabular}{|c|c|c|c|c|c|c|c|c|c|}
\hline \multirow{3}{*}{ 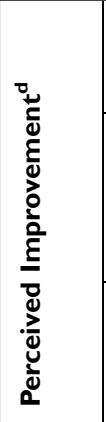 } & 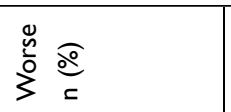 & $-\widehat{\widehat{\widehat{\Xi}}}$ & 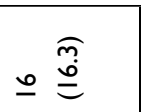 & $\bar{\sim} \stackrel{\widehat{\infty}}{\triangleq}$ & $\underline{\underline{\bar{m}}}$ & 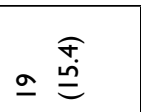 & $=\hat{\sigma}$ & 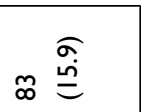 & \multirow{4}{*}{ 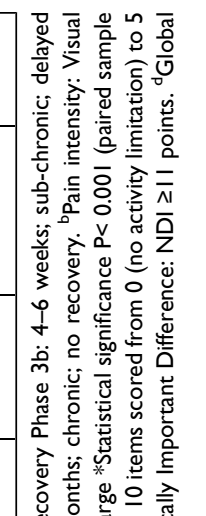 } \\
\hline & 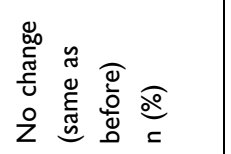 & $\begin{array}{r}\stackrel{\widehat{o}}{\infty} \\
+\stackrel{d}{d}\end{array}$ & 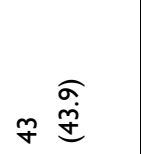 & 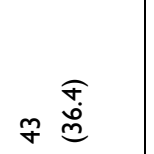 & 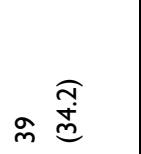 & 유 & 유 & 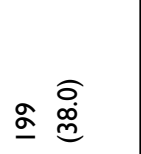 & \\
\hline & 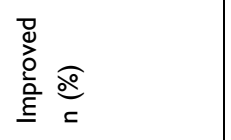 & 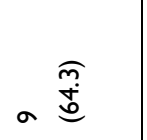 & مَ & 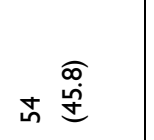 & ه & 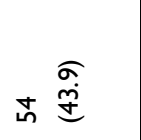 & $\sim \stackrel{\widehat{O}}{\stackrel{+}{+}}$ & $\overline{\overline{\dot{J}}}$ & \\
\hline \multirow{5}{*}{ 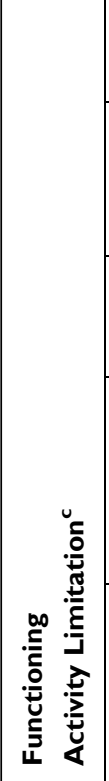 } & 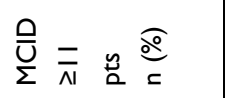 & $\infty \widehat{\bar{\pi}}$ & $\widehat{s} \stackrel{\substack{\sigma \\
0}}{0}$ & $n \frac{\sigma}{a}$ & 욤 & 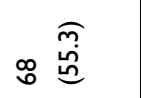 & 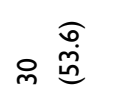 & $\frac{2}{m} \underset{\hat{g}}{\tilde{g}}$ & \\
\hline & 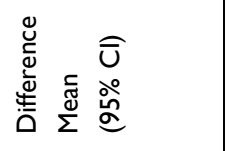 & 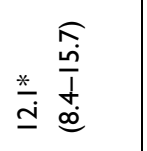 & 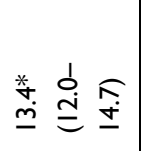 & $\stackrel{*}{\stackrel{*}{ \pm}} \stackrel{\frac{1}{\Xi}}{\Xi} \underset{m}{\underline{m}}$ & 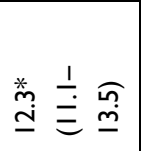 & 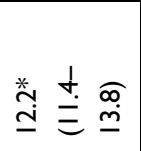 & 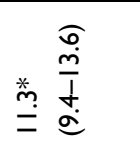 & 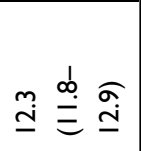 & 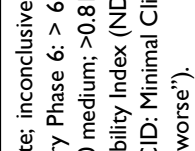 \\
\hline & 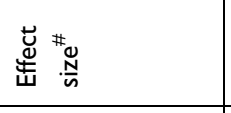 & $\stackrel{\infty}{\underline{m}}$ & $\stackrel{n}{=}$ & $\stackrel{\text { ָิ }}{\underline{I}}$ & 占 & $\stackrel{\circ}{\circ}$ & $\stackrel{\mathfrak{Y}}{\mathfrak{I}}$ & $\stackrel{\text { nq }}{-}$ & 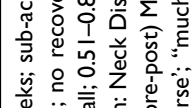 \\
\hline & 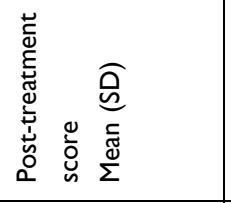 & 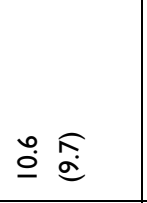 & 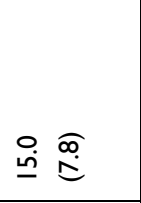 & 송 & 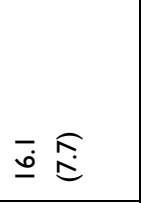 & $\begin{array}{l}\stackrel{\circ}{\circ} \\
\stackrel{\rho}{\infty} \stackrel{\infty}{\infty}\end{array}$ & $\begin{array}{l}\stackrel{\sigma}{\widehat{\infty}} \\
\underline{\infty}\end{array}$ & 官 & 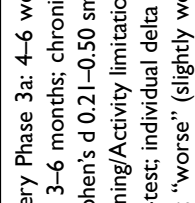 \\
\hline & 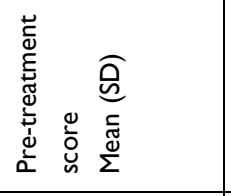 & 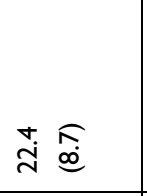 & $\stackrel{+}{\infty} \underset{\sim}{\stackrel{\Omega n}{\subseteq}}$ & 市 & $\stackrel{+}{\stackrel{\infty}{\infty}}$ & 孞 & 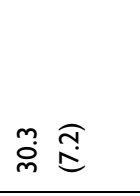 & 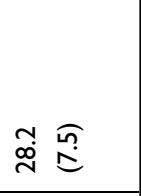 & 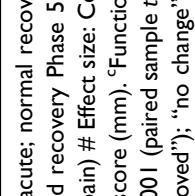 \\
\hline \multirow{5}{*}{ 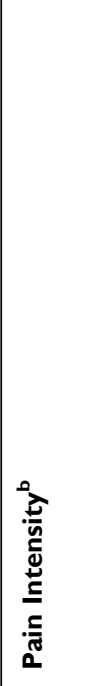 } & 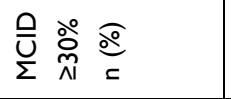 & $\simeq \stackrel{\substack{F \\
\stackrel{\leftrightarrow}{\infty}}}{\stackrel{\infty}{\infty}}$ & $\infty \stackrel{0}{\circ}$ & 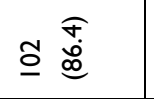 & 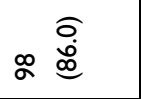 & 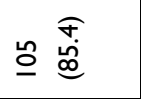 & \& & $\underset{q}{\stackrel{m}{\stackrel{f}{\infty}}}$ & 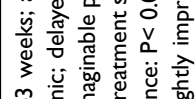 \\
\hline & 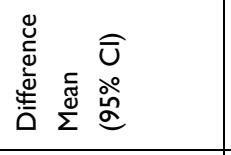 & 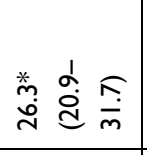 & 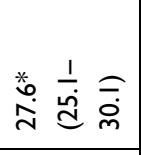 & 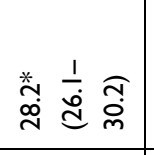 & 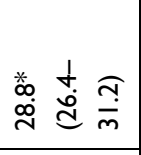 & 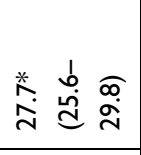 & 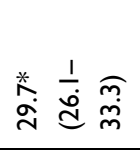 & 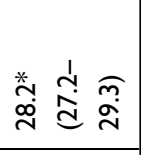 & 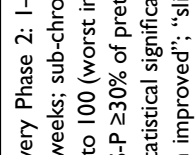 \\
\hline & 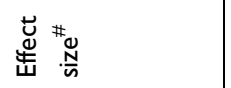 & $\stackrel{t}{\underline{t}}$ & $\stackrel{a}{a}$ & $\stackrel{ \pm}{\underline{N}}$ & ్ㅗ & $\frac{\infty}{i}$ & $\underset{\text { స }}{~}$ & $\bar{i}$ & 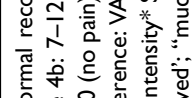 \\
\hline & 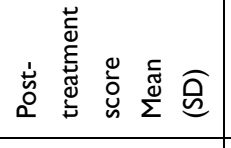 & 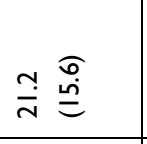 & 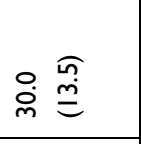 & 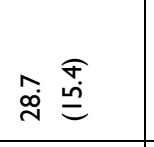 & $\overline{\stackrel{\text { N }}{\stackrel{O}{巳}}}$ & $\stackrel{\widehat{O}}{\stackrel{\dot{m}}{=}}$ & $\underset{\tilde{m}}{\widetilde{m}}=$ & 棉 & 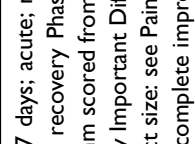 \\
\hline & 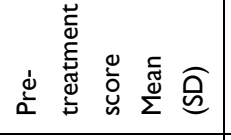 & 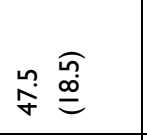 & $\stackrel{n}{\stackrel{0}{\dot{\dot{x}}}}$ & $\hat{\circ}$ & 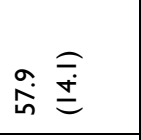 & 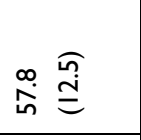 & 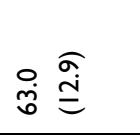 & $\stackrel{\infty}{i} \stackrel{\frac{1}{+}}{=}$ & 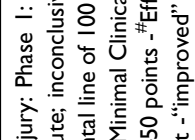 \\
\hline 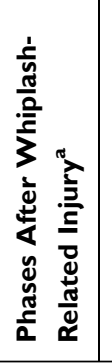 & $\stackrel{ఠ}{\complement}$ & 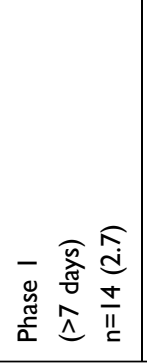 & 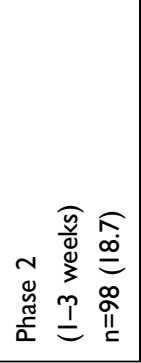 & 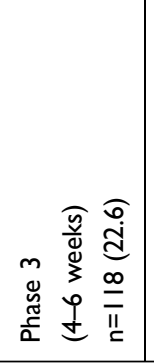 & 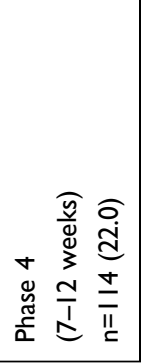 & 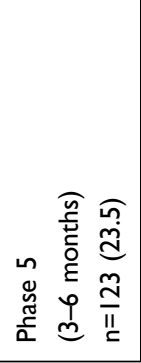 & 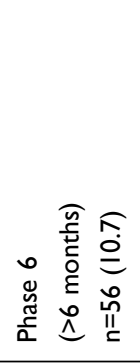 & 焉 & 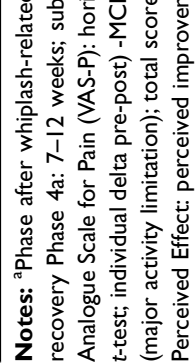 \\
\hline
\end{tabular}




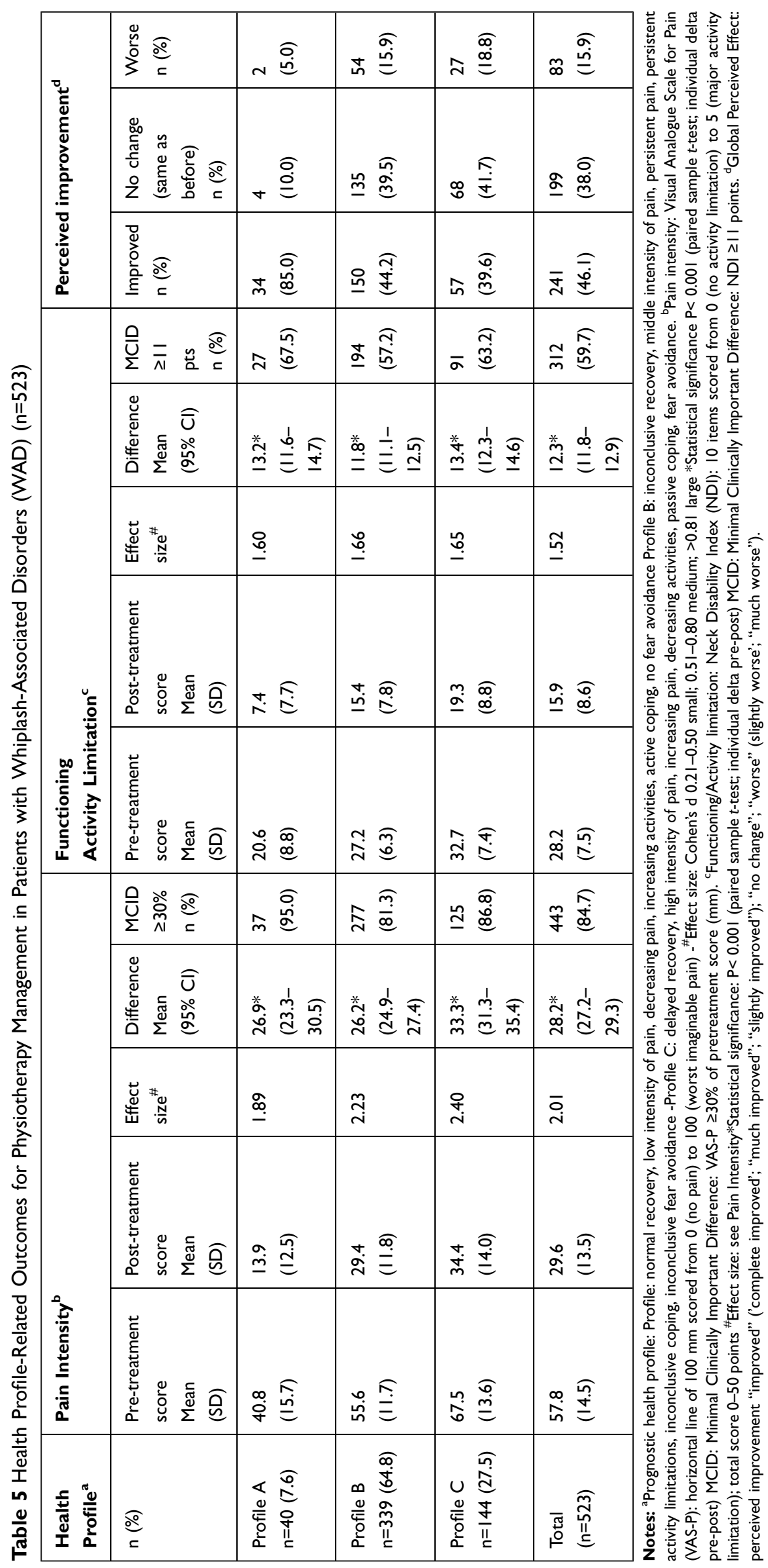


differs with the intensity of pain experienced. In retrospect, it might have been better to use a reduction in VAS-P of $20 \%$ for mild pain (VAS-P $\leq 30 \mathrm{~mm}$ ), $30 \%$ for moderate pain (VAS-P 31-60 mm) and 40\% for severe pain (VAS-P 61-100 mm). This variable "minimal" reduction probably corresponds more closely to patients' perception of their pain experience than a reduction of $\geq 30 \%$ of all initial scores. ${ }^{72}$

\section{Phases After Whiplash-Related Injury}

The time frame defined by the Quebec Task Force WAD ${ }^{4}$ guided the clinical management of patients in this study and other studies. The time frame, combined with prognostic factors, defined three profiles in relation to recovery. However, distinguishing between "normal recovery", "delayed recovery" or "no recovery" at the moment of referral was clinically difficult, and the distinction between "normal recovery" and "delayed recovery" was particularly unclear in the early phases after the whiplash injury. This resulted in the classification of more than half of the patients as 'uncertain recovery'. Nevertheless, the direction of recovery became clearer over the course of the treatment period and treatment sessions.

It was also apparent that the effect sizes for reduction of pain intensity in the later chronic phases were larger than those in the acute phases. A plausible explanation for this observation is that it is "easier" to lower a severe pain intensity score (VAS-P $>61 \mathrm{~mm}$ ) than a mild score (VAS-P $<30 \mathrm{~mm}$ ). Furthermore, patients with chronic pain are more often interested in reducing pain intensity than in increasing functioning.

The phases 4, 5 and 6 had a higher proportion of chronic cases relative to earlier phases. This finding is presumably associated with the outcome of worse functioning.

The percentage of patients showing "improvement", "no change" or "worse" was approximately equivalent across all phases. This emphasizes the superiority of classifications based on prognostic factors for recovery, which can be influenced by physiotherapy treatment, compared to time-related classifications in relation to whiplash-related injury.

\section{Prognostic Health Profile}

A definition of a prognostic health profile is a complex of positive and negative variables that can be used to estimate the chance of functional recovery in patients with WAD. ${ }^{27}$ The prognostic health profiles used here were based on the recognition of the clinical patterns of positive or negative prognostic factors for recovery. Five prognostic factors were included (course of recovery, pain intensity, functioning, coping, and fear avoidance). However, many other prognostics predict the outcome in patients with whiplash-related injury, such as pain intensity, widespread pain, sensory hypersensitivity, previous activity limitations, frequency of deterioration after previous treatment, history of previous neck injury, and behavioral and psychological factors. ${ }^{18,24,73-77}$ It is becoming increasingly clear that compensation and legal factors also often contribute to prognostics after whiplash-related injury. ${ }^{78}$ These factors were not included in the clinical estimation of prognostic patterns in this study.

It is not known how far the participating physiotherapists may have weighed all these prognostic factors when drawing up treatment plans, estimating the length of the treatment period, and determining the number of treatment sessions. Physiotherapists generally show a preference for dealing with mechanical aspects of whiplash injury, despite the growing recognition of psychological and cognitive factors as major contributing factors. ${ }^{79-82}$ In general, physiotherapists are inclined to overestimate the value of their own clinical assessment in their process of clinical reasoning and decision making, rather than applying guideline-based recommendations and using pre-treatment scores of pain intensity and functioning, and the risk scores of active or passive coping and fear avoidance.

Elements of prognostic health profiles were integrated into treatment goals and the choice of treatment modalities. For instance, positive prognostic factors (ie, low pain intensity, moderate activity limitation and active coping) were integrated into treatment goals for (acute) phases $1-3$, and negative prognostic factors (ie, increasing pain intensity, decreasing activities and passive coping) into treatment goals for (chronic) phases 4-6. However, a prognostic profile is often a mix of positive and negative factors, but may sometimes include mainly positive or mainly negative factors. Perceived complete or optimal improvement was reported by around $80 \%$ of the patients with mostly positive prognostic factors, about $40 \%$ with a mix of positive and negative prognostic factors, and $40 \%$ with negative prognostic factors, distributed over all phases.

It might be worthwhile to consider replacing clinical estimations of pain intensity, functioning, coping and fear avoidance in prognostic profiles with individual pre-treatment scores for pain intensity and functioning, together 
with risk scores for passive coping and fear avoidance. About $80 \%$ of the study population was at risk for passive coping and about $66 \%$ was at risk for pain avoiding behavior. In contrast to the prognostic profiles used here, scores on the PCI and FABQ were moderately but significantly associated with the PROs "pain intensity", "functioning" and "perceived improvement" in patients with WAD. ${ }^{36}$ Integration of these measurement scores into the clinical reasoning process and the treatment plan, goals and modalities in the physiotherapy assessment of patients with WAD would represent a further improvement.

A second consideration is the possible construction of a multicomponent prognostic sum score, analogous to the impairment sum score used in patients with reflex sympathetic dystrophy. ${ }^{83}$ Scores for pain, range of motion, temperature and volume were transformed into scores ranging from 1 to 10 , resulting in a sum score from 4 to 40 . The impairment sum score has been shown to be reliable, valid and responsive in patients with reflex sympathetic dystrophy. ${ }^{83}$ In a similar manner, it should be possible to convert generic (ie, VAS-P, PCI and FABQ) and nongeneric (ie, previous history of neck injury, type and number of whiplash-related symptoms, and NDI scores) prognostic factors into a sum score as a tool to steer treatment plans for WAD, and a comparable tool (risk assessment score) has already been developed by the Danish Whiplash Study Group. ${ }^{84}$ Optimizing physiotherapy treatment based on a sum score of generic and nongeneric prognostic factors is a challenge, but will likely improve the process of clinical reasoning, decision making, and outcomes in patients with WAD.

\section{Ceiling Effect of Physiotherapy Treatment} Nearly all patients reached the MCID value for pain intensity and more than half reached the MCID value for functioning in all phases after whiplash-related injury and in all prognostic health profiles. However, only about half of the patients experienced actual improvement. One plausible explanation is a "ceiling effect" in the treatment response.

International data indicate that approximately $50 \%$ of people who experience a whiplash accident will not recover but will continue to experience ongoing disability and pain at one year or longer after an accident. ${ }^{15-21}$ One plausible explanation is a ceiling effect for physiotherapy treatment in patients with WAD. Despite the poor prospects for recovery, treatment response remains an important issue. One of the conclusions of a recently published synthesis of the best available evidence in patients with neck pain, including WAD, was that different physiotherapy modalities or combinations of modalities have only small to moderate effect sizes in the short term, with low to moderate certainty of evidence. ${ }^{8}$ In the past twenty years, little real progress has been made in the "treatment-response" relationship in patients with WAD. Indeed, many reviews have called for further research in an effort to identify tractable factors associated with an optimal treatment response. However, despite a multitude of studies, treatment effectiveness and treatment outcomes after a whiplash-related injury are still a matter of considerable debate. One possible resolution of this question is the contention that an optimal treatment response relationship has already been achieved.

\section{Limitations}

The principal limitations of this retrospective cohort study were involvement of only two primary care physiotherapy practices in the Netherlands, and data were collected by eight physiotherapists in total. These two practices are specialized in the assessment and management of patients with WAD. While the characteristics of the participating physiotherapists were comparable to the national average72 and the patient sample was comparable to participants in other Dutch studies, ${ }^{66-68}$ the low number of participating practices and physiotherapists may have limited generalizability of the results.

The dataset was checked in 2016 for completeness and actuality. The content of the pen and paper patient record was confirmed on the basis of Dutch guidelines "Physiotherapy Documentation", as published in $2016^{30}$ and in 2019. ${ }^{31}$ Although the pen and paper record has now been replaced by electronic patient documentation, ${ }^{85}$ the pen and paper record used in this study still meets the requirements of the most recent Dutch CPG Physiotherapy Documentation. ${ }^{31}$ Despite the limitations of RCD studies generally, including this RCD-WAD study, the expectation was that the results of this study could plausibly represent insights into the PROs and treatment-related outcomes in patients with WAD anno 2020. In order to assess the quality of our study using the RCD-WAD, we compared the text to the criteria of the RECORD statement and found that most criteria were met. ${ }^{86,87}$

Another limitation of this study was the length of follow-up, which was limited to one or two contacts within a few months of discharge. With regard to primary care physiotherapy, the Dutch health care system sets a 
maximum number of sessions and does not allow for longer follow-up. The variability in pain and functioning found in patients in long-term studies ${ }^{16,18}$ can presumably be extrapolated to the patient population in the present study. However, due to an incomplete understanding of the long-term variability of symptoms and functioning beyond the treatment period, it is very difficult to give patients a realistic personal outlook regarding long-term functioning. Nonetheless, electronic tools can be used to define MCIDs for pain intensity and functioning, which in turn provide useful individual information on whether the patient shows a meaningful improvement or a worsening of pain and functioning over time.

In contrast to longitudinal studies, ${ }^{19-21}$ our study only included data gathered during the treatment episode, without additional follow-up. Within these limitations, about half of the patients improved while the other half were categorized as "no change" or "worse", without meaningful differences related to year of treatment or phase after whiplash-related injury. Based on the results of longitudinal studies of functional recovery after whiplash-related injury, it seems unlikely that recovery rates will improve substantially in the future. International data also indicate that approximately 50\% of people involved in a whiplash accident will not recover and will continue to experience ongoing activity limitations and long-term neck pain.

\section{Conclusion}

This study highlighted the integration of PROMs and PROs as quality indicators in the clinical reasoning process in the management of patients with WAD. These recommended measurements were successfully applied in two primary care physiotherapy practices over a period of 10 years, across all phases after whiplash-related accident and with different prognostic health profiles.

Statistically and clinically important differences in pain intensity and functioning were found but were unrelated to year of referral, phase after whiplash-related injury or prognostic health profile.

The MCID VAS-P score did not differ depending on experienced pain.

Finally, improving the integration of the consensusbased PROMs that underpin the process of clinical reasoning in patients with WAD will improve the homogeneity and comparability of data collected in primary care physiotherapy practice.

\section{Author Contributions}

All authors made a significant contribution to the work reported, whether that is in the conception, study design, execution, acquisition of data, analysis and interpretation, or in all these areas; took part in drafting, revising or critically reviewing the article; gave final approval of the version to be published; have agreed on the journal to which the article has been submitted; and agree to be accountable for all aspects of the work.

\section{Disclosure}

The authors report no conflicts of interest in this work.

\section{References}

1. Bovim G, Schrader H, Sand T. Neck pain in the general population. Spine. 1994;19(12):1307-1309. doi:10.1097/00007632-19940600000001

2. Carroll LJ, Hogg-Johnson S, van der Velde G, et al. Bone and joint decade 2000-2010 task force on neck pain and its associated disorders. Course and prognostic factors for neck pain in the general population: results of the bone and joint decade 2000-2010 task force on neck pain and its associated disorders. Spine. 2008;33(4Suppl): S75-82. doi:10.1097/BRS.0b013e31816445be

3. Croft PR, Lewis M, Papageorgiou AC, et al. Risk factors for neck pain: a longitudinal study in the general population. Pain. 2001;93 (3):317-325. doi:10.1016/S0304-3959(01)00334-7

4. Spitzer WO, Skovron ML, Salmi LR, et al. Scientific monograph of the quebec task force on whiplash-associated disorders: redefining "whiplash" and its management. Spine. 1995;20(8Suppl):1S-73S.

5. Carroll LJ, Holm LW, Hogg-Johnson S, et al. Course and prognostic factors for neck pain in whiplash-associated disorders (WAD): results of the bone and joint decade 2000-2010 task force on neck pain and its associated disorders. Spine. 2008;33(4Suppl):S83-92. doi:10.1097/BRS.0b013e3181643eb8

6. Hurwitz EL, Carragee EJ, van der Velde G, et al. Bone and joint decade 2000-2010 task force on neck pain and its associated disorders. treatment of neck pain: noninvasive interventions: results of the bone and joint decade 2000-2010 task force on neck pain and its associated disorders. Spine. 2008;33(4Suppl):S123-152. doi:10.1097/ BRS.0b013e3181644b1d

7. Sterling M. Physiotherapy management of whiplash-associated disorders (WAD). J Physiother. 2014;60:5-12. doi:10.1016/j.jphys.2013.12.004

8. Sterling M, de Zoete RMJ, Coppieters I, Farrell SF. Best evidence rehabilitation for chronic pain part 4: neck pain. J Clin Med. 2019;8 (8):pii: E1219. doi:10.3390/jcm8081219

9. Kyte DG, Calvert M, van der Wees PJ, Ten Hove R, Tolan S, Hill JC. An introduction to patient-reported outcome measures (PROMs) in physiotherapy. Physiotherapy. 2015;101(2):119-125. doi:10.1016/j. physio.2014.11.003

10. Mercieca-Bebber R, King MT, Calvert MJ, Stockler MR, Friedlander $M$. The importance of patient-reported outcomes in clinical trials and strategies for future optimization. Patient Relat Outcome Meas. 2018;9:353-367. doi:10.2147/PROM.S156279

11. Patient-reported outcome. Available from: https://en.wikipedia.org/ wiki/Patient-reported_outcome. Accessed April 18, 2020.

12. Verburg AC, van Dulmen SA, Kiers H, Nijhuis-van der Sanden MWG, van der Wees PJ. Development of a standard set of outcome measures for non-specific low bac pain in Dutch primary care physiotherapy practices: a Delphi study. Eur Spine J. 2019;28(7):15501564. doi:10.1007/s00586-019-05962-x 
13. van Dulmen SA, van der Wees PJ, Staal JB, Braspenning JCC, Nijhuis-van der Sanden MWG. Patient reported outcome measures (PROMs) for goalsetting and outcome measurement in primary care physiotherapy, an explorative field study. Physiotherapy. 2017;103 (1):66-72. doi:10.1016/j.physio.2016.01.001

14. Lawrence M, Olesen F. Indicators of quality health care. Eur J Gen Pract. 1997;3:103-108. doi:10.3109/13814789709160336

15. Kasch H, Qerama E, Kongsted A, Bendix T, Jensen TS, Bach FW. Clinical assessment of prognostic factors for long-term pain and handicap after whiplash injury: a 1-year prospective study. Eur $J$ Neurol. $\quad 2008 ; 15(11): 1222-1230 . \quad$ doi:10.1111/j.1468-1331.2008. 02301.x

16. Myrtveit SM, Carstensen T, Kasch H, Ørnbøl E, Frostholm L. Initial healthcare and coping preferences are associated with outcome 1 year after whiplash trauma: a multicentre 1-year follow-up study. $B M J$ Open. 2015;5(3):e007239. doi:10.1136/bmjopen-2014-007239

17. Gehrt TB, Wisbech Carstensen TB, Ørnbøl E, Fink PK, Kasch H, Frostholm L. The role of illness perceptions in predicting outcome after acute whiplash trauma: a multicenter 12-month follow-up study. Clin J Pain. 2015;31(1):14-20. doi:10.1097/AJP.0000000000000085

18. Åsenlöf P, Bring A, Söderlund A. The clinical course over the first year of whiplash associated disorders (WAD): pain-related disability predicts outcome in a mildly affected sample. BMC Musculoskelet Disord. 2013;14:361. doi:10.1186/1471-2474-14-361

19. Styrke J, Sojka P, Björnstig U, Stålnacke BM. Symptoms, disabilities, and life satisfaction five years after whiplash injuries. Scand J Pain. 2014;5(4):229-236. doi:10.1016/j.sjpain.2014.06.001

20. Squires B, Gargan MF, Bannister GC. Soft-tissue injuries of the cervical spine. 15-year follow-up. J Bone Joint Surg Br. 1996;78 (6):955-957. doi:10.1302/0301-620X.78B6.0780955

21. Bunketorp L, Nordholm L, Carlsson J. A descriptive analysis of disorders in patients 17 years following motor vehicle accidents. Eur Spine J. 2002;11(3):227-234. doi:10.1007/s00586-002-0393-y

22. Carroll LJ, Hogg-Johnson S, Cote P, et al. Course and prognostic factors for neck pain in workers: results of the bone and joint decade 2000-2010 task force on neck pain and lts associated disorders. Spine. 2008;33(4Suppl):S93-S100. doi:10.1097/BRS.0b013e31816445d4

23. Kamper SJ, Rebbeck TJ, Maher CG, McAuley JH, Sterling M. Course and prognostic factors of whiplash: a systematic review and meta-analysis. Pain. 2008;138(3):617-629. doi:10.1016/j.pain.20 08.02 .019

24. Walton DM, Pretty J, MacDermid JC, Teasell RW. Risk factors for persistent problems following whiplash injury: results of a systematic review and meta-analysis. J Orthop Sports Phys Ther. 2009;39 (5):334-350. doi:10.2519/jospt.2009.2765

25. Bekkering GE, Hendriks HJM, Lanser K, et al. KNGF-richtlijn Whiplash (KNGF guideline Whiplash). Ned Tijdschr Fysiother. 2001;111(Supplement):S1-S25.

26. Scholten-Peeters GGM, Bekkering GE, Verhagen AP, et al. Clinical practice guideline for the physiotherapy of patients with whiplashassociated disorders. Spine. 2002;27(4):412-422. doi:10.1097/ 00007632-200202150-00018

27. Vaes P, Kerckhofs E, Beckwée D, Oostendorp RAB. Definitie Gezondheidsprofiel (Definition Health Profile). In: Gezondheidsprofiel (Health Profile). Vaes P, Kerckhofs E, Beckwée, Edited by. Antwerpen: Standaard Uitgeverij; 2011:pp42-61.

28. Koninklijk Nederlands Genootschap Fysiotherapie. Richtlijnen Voor De Fysiotherapeutische Verslaglegging (KNGF-Guidelines Physiotherapy Documation). Amersfoort: KNGF; 1993.

29. Heerkens YF, Lakerveld-Heyl K, Verhoeven ALJ, Hendriks HJM. KNGF-richtlijn Fysiotherapeutische Verslaglegging (KNGFGuidelines Physiotherapy Documation). Ned Tijdschr Fysiother. 2007;117(6):Supplement 1-20.

30. Koninklijk Nederlands Genootschap Fysiotherapie. KNGF-Richtlijn Fysiotherapeutische Dossiervorming (KNGF-Guidelines Physiotherapy Documentation). Amersfoort: KNGF; 2016.
31. Koninklijk Nederlands Genootschap Fysiotherapie. KNGF-Richtlijn Fysiotherapeutische Dossiervorming (KNGF-Guideline Physiotherapy Documentation). Amersfoort: KNGF; 2019.

32. Bier JD, Scholten-Peeters GGM, Staal JB, et al. KNGF-Richtlijn Nekpijn. Amersfoort: KNGF; 2016.

33. Bier JD, Scholten-Peeters GGM, Staal JB, et al. Clinical practice guideline for physical therapy assessment and treatment in patients with nonspecific neck pain. Phys Ther. 2018;98(3):162-171. doi:10.1093/ptj/pzx118

34. Scholten-Peeters GG, Verhagen AP, Neeleman-van der Steen CW, Hurkmans JC, Wams RW, Oostendorp RA. Randomized clinical trial of conservative treatment for patients with whiplash-associated disorders: considerations for the design and dynamic treatment protocol. J Manipulative Physiol Ther. 2003;26(7):412-420. doi:10.1016/ S0161-4754(03)00092-7

35. Oostendorp RAB, Elvers JWH, van Trijffel E, et al. Has the quality of physiotherapy care in patients with Whiplash-associated disorders (WAD) improved over time? A retrospective study using routinely collected data and quality indicators. Patient Prefer Adherence. 2018;12:2291-2308. doi:10.2147/PPA.S179808

36. Oostendorp RAB, Elvers JWH, van Trijffel E, et al. Relationships between context, process, and outcome indicators to assess quality of physiotherapy care in patients with whiplash-associated disorders: applying donabedian's model of care. Patient Prefer Adherence. 2020;14:425-442. doi:10.2147/PPA.S234800

37. Mathieson K. Making sense of biostatistics: making sense of biostatistics: types of nonprobability sampling. J Clin Res Best Pract. 2014;10(10). Available from: https://firstclinical.com/journal.

38. Kraaimaat FW, Bakker A, Evers AMW. Pijncoping-strategieën bij chronische pijnpatiënten. De ontwikkeling van de Pijn-Coping-lnventarisatielijst (PCI). [Pain-coping strategies in chronic pain patients: the development of the Pain Coping lnventory (PCI)]. Gedragstherapie. 1997;30:185-201.

39. Kraaimaat FW, Evers AW. Pain-coping strategies in chronic pain patients: psychometric characteristics of the pain-coping inventory (PCI). Int $J$ Behav Med. 2003;10(4):343-363. doi:10.1207/S15327558IJBM1004 5

40. Waddell G, Newton M, Henderson I, Somerville D, Main CJ, FearAvoidance Beliefs A. Questionnaire (FABQ) and the role of fearavoidance beliefs in chronic low back pain and disability. Pain. 1993;52(2):157-168. doi:10.1016/0304-3959(93)90127-B

41. Vendrig A, Deutz P, Vink L. Nederlandse vertaling en bewerking van de fear-avoidance beliefs questionnaire. Ned Tijdschr Pijn Pijnbestr. 1998;18(1):11-14.

42. Peeters GG, Verhagen AP, de Bie RA, Oostendorp RA. The efficacy of conservative treatment in patients with whiplash injury: a systematic review of clinical trials. Spine. 2001;26(4):E64-73. doi:10.1097/ 00007632-200102150-00006

43. Verhagen AP, Scholten-Peeters GG, de Bie RA, Bierma-Zeinstra SM. Conservative treatments for whiplash. Cochrane Database Syst Rev. 2004(1):CD003338

44. Seferiadis A, Rosenfeld M, Gunnarsson R. A review of treatment interventions in whiplash-associated disorders. Eur Spine J. 2004;13 (5):387-397. doi:10.1007/s00586-004-0709-1

45. Kongsted A, Qerama E, Kasch H, et al. Neck collar, "act-as-usual" or active mobilization for whiplash injury? A randomized parallel-group trial. Spine (Phila Pa 1976. 2007;32(6):618-626. doi:10.1097/01. brs.0000257535.77691.bd

46. Goldsmith CH, Gross AR, MacDermid J, Santaguida PL, Miller J. What does the evidence tell us about design of future treatment trials for whiplash-associated disorders? Spine (Phila Pa 1976. 2011;36(25 Suppl):S292-302. doi:10.1097/BRS.0b013e3182388259

47. Rushton A, Wright C, Heneghan N, Eveleigh G, Calvert M, Freemantle N. Physiotherapy rehabilitation for whiplash associated disorder II: a systematic review and meta-analysis of randomised controlled trials. BMJ Open. 2011;1(2):e000265. doi:10.1136/bmjopen-2011-000265 
48. Pietrobon R, Coeytaux RR, Carey TS, Richardson WJ, DeVellis RF Standard scales for measurement of functional outcome for cervical pain or dysfunction: a systematic review. Spine. 2002;27(5):515-522. doi:10.1097/00007632-200203010-00012

49. Wewers ME, Lowe NK. A critical review of visual analogue scales in the measurement of clinical phenomena. Res Nurs Health. 1990;13 (4):227-236. doi:10.1002/nur.4770130405

50. Kamper SJ, Grootjans SJ, Michaleff ZA, Maher CG, McAuley JH, Sterling M. Measuring pain intensity in patients with neck pain: does it matter how you do it? Pain Pract. 2015;15(2):159-167. doi:10.1111/papr.12169

51. Ostelo RWJG, De Vet HCW. Clinically important outcomes in low back pain. Best Pract Res Clin Rheumatol. 2005;19(4):593-607. doi:10.1016/j.berh.2005.03.003

52. Pool JJ, Ostelo RW, Hoving JL, Bouter LM, de Vet HC. Minimal clinically important change of the neck disability index and the numerical rating scale for patients with neck pain. Spine. 2007;32 (26):3047-3051. doi:10.1097/BRS.0b013e31815cf75b

53. Carlsson AM. Assessment of chronic pain. I. Aspects of the reliability and validity of the visual analogue scale. Pain. 1983;16(1):87101. doi:10.1016/0304-3959(83)90088-X

54. Hawker GA, Mian S, Kendzerska T, French M. Measures of adult pain: Visual Analog Scale for Pain (VAS Pain), Numeric Rating Scale for Pain (NRS Pain), McGill Pain Questionnaire (MPQ), Short-Form McGill Pain Questionnaire (SF-MPQ), Chronic Pain Grade Scale (CPGS), Short Form-36 Bodily Pain Scale (SF-36 BPS), and Measure of Intermittent and Constant Osteoarthritis Pain (ICOAP). Arthritis Care Res. 2011;63(Suppl 11):S240-252. doi:10.1002/acr.20543

55. Vernon H, Mior S. The neck disability index: a study of reliability and validity. J Manip Physiol Ther. 1991;14(7):409-415.

56. Vernon H. The neck disability index: state-of-the-art, 1991-2008. J Manip Physiol Ther. 2008;31(7):491-502. doi:10.1016/j.jmpt.2008.08.006

57. Young BA, Walker MJ, Strunce JB, Boyles RE, Whitman JM, Childs JD. Responsiveness of the neck disability index in patients with mechanical neck disorders. Spine J. 2009;9(10):802-808. doi:10.1016/j.spinee.2009.06.002

58. Hoving JL, O'Leary EF, Niere KR, Green S, Buchbinder R. Validity of the neck disability index, Northwick Park neck pain questionnaire, and problem elicitation technique for measuring disability associated with whiplash-associated disorders. Pain. 2003;102(3):273-281. doi:10.1016/S0304-3959(02)00406-2

59. Schellingerhout JM, Verhagen AP, Heymans MW, Koes BW, de Vet $\mathrm{HC}$, Terwee CB. Measurement properties of disease-specific questionnaires in patients with neck pain: a systematic review. Qual Life Res. 2012;21(4):659-670. doi:10.1007/s11136-011-9965-9

60. Koke AJA, Heuts PHTG, Vlaeyen JWS. Neck Disability Index. Pain Knowledge Center, University Medical Center Maastricht, Measurement Instruments Chronic Pain. Maastricht: Pijn Kennis Centrum, Academisch Ziekenhuis Maastricht; 1996.

61. Jorritsma W, de Vries GE, Dijkstra PU, Geertzen JH, Reneman MF. Neck pain and disability scale and neck disability index: validity of dutch language versions. Eur Spine J. 2012;21(1):93-100. doi:10.1007/s00586-011-1920-5

62. Jorritsma W, de Vries GE, Geertzen JH, Dijkstra PU, Reneman MF. Neck pain and disability scale and the neck disability index: reproducibility of the Dutch language versions. Eur Spine J. 2010;19:16951701. doi:10.1007/s00586-010-1406-x

63. Kamper SJ, Ostelo RW, Knol DL, Maher CG, de Vet HC, Hancock MJ. Global perceived effect scales provided reliable assessments of health transition in people with musculoskeletal disorders, but ratings are strongly influenced by current status. J Clin Epidemiol. 2010;63 (7):760-766. doi:10.1016/j.jclinepi.2009.09.009

64. Portney LG, Watkins. Foundations of Clinical Research. Applications to Practice. Appleton \& Lange; Norwalk: Connecticut; 1993:651657.
65. Scholten-Peeters GG, Neeleman-van der Steen CW, van der Windt DA, Hendriks EJ, Verhagen AP, Oostendorp RA. Education by general practitioners or education and exercises by physiotherapists for patients with whiplash-associated disorders? A randomized clinical trial. Spine. 2006;31(7):723-731. doi:10.1097/01.brs.0000206 381.15224.0f

66. Hoving JL, Koes BW, de Vet HC, et al. Manual therapy, physical therapy, or continued care by a general practitioner for patients with neck pain. A randomized, controlled trial. Ann Intern Med. 2002;136 (10):713-722. doi:10.7326/0003-4819-136-10-200205210-00006

67. Pool JJ, Ostelo RW, Knol DL, Vlaeyen JW, Bouter LM, de Vet HC. Is a behavioral graded activity program more effective than manual therapy in patients with subacute neck pain? Results of a randomized clinical trial. Spine. 2010;35(10):1017-1024. doi:10.1097/ BRS.0b013e3181c212ee

68. Peters R, Mutsaers B, Verhagen AP, Koes BW, Pool-Goudzwaard AL. Prospective cohort study of patients with neck pain in a manual therapy setting: design and baseline measures. J Manip Physiol Ther. 2019;42(7):471-479. doi:10.1016/j.jmpt.2019.07.001

69. Bunketorp L, Stener-Victorin E, Carlsson J. Neck pain and disability following motor vehicle accidents - a cohort study. Eur Spine J. 2005;14(1):84-89. doi:10.1007/s00586-004-0766-5

70. Meisingset I, Stensdotter AK, Woodhouse A, Vasseljen O. Predictors for global perceived effect after physiotherapy in patients with neck pain: an observational study. Physiotherapy. 2018;104(4):400-407. doi:10.1016/j.physio.2017.01.007

71. Van Hassel DTP, Kenens RJ. Cijfers uit de registratie van fysiotherapeuten. Peiling Januari; 2012. Availabie from: https://www.nivel.nl/ nl/publicatie/cijfers-uit-de-registratie-van-fysiotherapeuten-de-eerstelijn-peiling-1-januari-2012. Accessed April 19, 2020.

72. Kelly AM. The minimum clinically significant difference in visual analogue scale pain score does not differ with severity of pain. Emerg Med J. 2001;18(3):205-207. doi:10.1136/emj.18.3.205

73. Sterling M, Jull G, Vicenzino B, Kenardy J, Darnell R. Physical and psychological factors predict outcome following whiplash injury. Pain. 2005;114(1-2):141-148. doi:10.1016/j.pain.2004.12.005

74. Scott D, Jull G, Sterling M. Widespread sensory hypersensitivity is a feature of chronic whiplash-associated disorder but not chronic idiopathic neck pain. Clin J Pain. 2005;21(2):175-181. doi:10.1097/ 00002508-200503000-00009

75. Sterling M, Jull G, Vicenzino B, Kenardy J. Sensory hypersensitivity occurs soon after whiplash injury and is associated with poor recovery. Pain. 2003;104(3):509-517. doi:10.1016/S0304-3959(03) 00078-2

76. De Pauw R, Kregel J, De Blaiser C, et al. Identifying prognostic factors predicting outcome in patients with chronic neck pain after multimodal treatment: a retrospective study. Man Ther. 2015;20 (4):592-597. doi:10.1016/j.math.2015.02.001

77. Hendriks EJ, Scholten-Peeters GG, van der Windt DA, et al. Prognostic factors for poor recovery in acute whiplash patients. Pain. 2005;114(3):408-416. doi:10.1016/j.pain.2005.01.006

78. Dufton JA, Bruni SG, Kopec JA, Cassidy JD, Quon J. Delayed recovery in patients with whiplash-associated disorders. Injury. 2012;43(7):1141-1147. doi:10.1016/j.injury.2012.03.006

79. Synnott A, O'Keeffe M, Bunzli S, Dankaerts W, O'Sullivan P, O'Sullivan K. Physiotherapists may stigmatise or feel unprepared to treat people with low back pain and psychosocial factors that influence recovery: a systematic review. J Physiother. 2015;61(2):68-76. doi:10.1016/j.jphys.2015.02.016

80. Zadro J, O'Keeffe M, Maher C. Do physical therapists follow evidence-based guidelines when managing musculoskeletal conditions? Systematic review. BMJ Open. 2019;9(10):e032329. doi:10.1136/ bmjopen-2019-032329

81. Sterling M, Kenardy J, Jull G, Vicenzino B. The development of psychological changes following whiplash injury. Pain. 2003;106 (3):481-489. doi:10.1016/j.pain.2003.09.013 
82. Nijs J, Roussel N, van Wilgen PC, Köke A, Smeets R. Thinking beyond muscles and joints: therapists' and patients' attitudes and beliefs regarding chronic musculoskeletal pain are key to applying effective treatment. Man Ther. 2013;18(2):96-102. doi:10.1016/j. math.2012.11.001

83. Oerlemans HM, Goris RJ, Oostendorp RA. Impairment level sum score in reflex sympathetic dystrophy of one upper extremity. Arch Phys Med Rehabil. 1998;79(8):979-990. doi:10.1016/S0003-9993 (98)90098-3

84. Kasch H, Kongsted A, Qerama E, et al. A new stratified risk assessment tool for whiplash injuries developed from a prospective observational study. BMJ Open. 2013;3:e02050. doi:10.1136/bmjopen2012-002050
85. Coons SJ, Gwaltney CJ, Hays RD, et al. ISPOR ePRO Task Force. Recommendations on evidence needed to support measurement equivalence between electronic and paper-based patient-reported outcome (PRO) measures: ISPOR ePRO Good Research Practices Task Force report. Value Health. 2009;12(4):419-429. doi:10.1111/j.15244733.2008.00470.x

86. Benchimol E, Smeeth L, Guttmann A, et al. The REporting of studies Conducted using Observational Routinely-collected health Data (RECORD) statement. PLoS Med. 2015;12(10):e1001885. doi:10.1371/journal.pmed.1001885

87. Langan SM, Cook C, Benchimol EI. lmproving the reporting of studies using routinely collected health data in physical therapy. J Orthop Sports Phys Ther. 2016;46(3):126-127. doi:10.2519/jospt.2016.0103

\section{Publish your work in this journal}

Patient Preference and Adherence is an international, peer-reviewed, open access journal that focusing on the growing importance of patient preference and adherence throughout the therapeutic continuum. Patient satisfaction, acceptability, quality of life, compliance, persistence and their role in developing new therapeutic modalities and compounds to optimize clinical outcomes for existing disease states are major areas of interest for the journal. This journal has been accepted for indexing on PubMed Central. The manuscript management system is completely online and includes a very quick and fair peer-review system, which is all easy to use. Visit http:// www.dovepress.com/testimonials.php to read real quotes from published authors. 